\title{
Sweet syndrome
}

INSERM

\section{Source}

INSERM. (1999). Orphanet: an online rare disease and orphan drug data base. Sweet syndrome. ORPHA:3243

Sweet's syndrome (the eponym for acute febrile neutrophilic dermatosis) is characterized by a constellation of clinical symptoms, physical features, and pathologic findings which include fever, neutrophilia, tender erythematous skin lesions (papules, nodules, and plaques), and a diffuse infiltrate consisting predominantly of mature neutrophils that are typically located in the upper dermis. 